\title{
BANCO DE DADOS DE TEATRO EM COMUNIDADES: GARIMPANDO O TEATRO DE SÃO GONÇALO DO BAÇÃOO. ${ }^{1}$
}

\author{
Márcia Pompeo Nogueira²; Mário César Coelho Gomes ${ }^{3}$.
}

RESUMO: Procura entender como as culturas populares interagem dentro de uma prática teatral em comunidades, através do estudo de caso realizado acerca do Grupo de Teatro de São Gonçalo do Bação. Inicia fazendo um apanhado histórico para o entendimento do contexto em que o grupo está inserido, trata ainda de seus processos de criação e por fim estabelece um paralelo entre o trabalho do grupo e as culturas populares.

PALAVRAS - CHAVE: Teatro em comunidades; Grupo de Teatro de São Gonçalo do Bação; criação coletiva; culturas populares.

\section{Que ‘trem' é esse?: Introdução}

O "Banco de dados para o desenvolvimento do teatro em comunidades" é um projeto de pesquisa que inclui um questionário online onde os grupos que atuam em comunidades podem colocar informações referentes ao seu trabalho.

Esta pesquisa representa o aprofundamento de informações de um dos grupos pertencentes ao banco de dados. Nos interessamos pelo grupo em função de sua origem rural. Então, no primeiro semestre de 2008 entramos em contato por $e$-mail e assim agendamos uma visita do bolsista Mário César Coelho Gomes ao grupo.

Tal visita ocorreu entre os dias 05 e 09 de junho de 2008. Lá realizaram-se entrevistas com os integrantes do grupo e da comunidade e com Ramon Aguiar, além de registros fotográficos e filmagens do trabalho.

\section{Onde se formam as gemas: Contexto.}

\footnotetext{
${ }^{1}$ Projeto de pesquisa: "Banco de dados para o desenvolvimento do teatro em comunidades", CEART/UDESC. ${ }^{2}$ Orientador, Professor do Departamento de Artes Cênicas - CEART/UDESC.

${ }^{3}$ Acadêmico do curso de Licenciatura em Ed. Artística - Habilitação: Artes Cênicas do CEART/UDESC e bolsista PIBIC/CNPq.
} 
Início do século XVIII. O hoje notório município de Ouro Preto, era conhecido então como Vila Rica e configurava-se à época como a capital da Capitania das Minas Gerais. Neste período, algumas das regiões, que no presente existem enquanto municípios, eram administradas por Vila Rica. Dentre elas inclui-se o arraial de Itabira do Campo, região que compreende hoje ao município de Itabirito. São Gonçalo do Bação é um distrito rural de Itabirito. Fundado possivelmente entre os anos de 1730 e 1740 pelo português Antônio Alves Vação, que nesse período explorava o ouro de aluvião ${ }^{4}$ surdido dos rios daquelas terras.

A oralidade local revela que o nome do distrito surge de uma promessa feita por Antonio Alves Vação à São Gonçalo. Reza a estória contada até hoje, que Vação prometeu que tendo sua graça concedida construiria uma capela na localidade para abrigar uma imagem do santo. Pois bem, graça alcançada restou ao português cumprir a promessa. Colocando a imagem do santo nos quartos de um burro, soltou o animal pelas redondezas. O local escolhido por este para parada seria o mesmo de construção da capela. Tal feito concluiu-se por volta de 1740 .

A capela se constitui como um símbolo forte da localidade, pois é a partir de sua construção e em torno dela que o distrito se desenvolve e, séculos mais tarde, também o próprio grupo de teatro, pois foi lá que este começou e é lá que apresenta até hoje suas peças.

O nome do distrito provém da estória contada sobre Antonio Alves Vação, sendo São Gonçalo oriundo do nome do santo que se fez a promessa e Bação por conta da apropriação popular ao sobrenome Vação (AGUIAR, 2006: 25) do português.

\section{Uma corrente valiosa. Elos diversos.}

Sabe-se também que São Gonçalo do Bação localizava-se em uma região distante apenas 54 quilômetros da então capital Vila Rica e, além disso, o distrito era abundante em minérios tornando-se até mesmo produtor de ouro de aluvião.

\footnotetext{
${ }^{4}$ Ouro garimpado no fundo dos rios.
} 
Este cenário fez com que o local possuísse um importante trânsito de pessoas, como por exemplo, ciganos, andarilhos e os tropeiros, comerciantes que viajam por vários lugares e que acabaram utilizando São Gonçalo como ponto de passagem e parada.

Tais fatos começaram a desenhar uma forte característica de recepção e inclusão do "estrangeiro" por parte da comunidade. Particularidade que é reforçada por outros acontecimentos. Na década de 1970 quatro casais de filosofia hyppie (AGUIAR, 2006) chegam a São Gonçalo, trazendo consigo suas visões de mundo. Eles acabam transferindo costumes/comportamento e novos hábitos - como o do artesanato - à comunidade. Tendo sido bem recebidos, hoje fazem parte da mesma e inclusive do grupo de teatro.

Observamos que a interpenetração cultural é historicamente uma constante dentro da comunidade de São Gonçalo do Bação. Uma possibilidade para a análise da interpenetração entre as culturas é a classificação de Arjun Appadurai citada pelo antropólogo argentino Néstor Garcia Canclini em seu livro, Consumidores e Cidadãos: conflitos multiculturais da globalização (2005).

Segundo esta classificação, podemos observar pelo menos cinco processos pelos quais a heterogeneidade cultural, a troca de informações e a resignificação dos símbolos de cada sociedade podem ser percebidos: ethnoscapes, technoscapes, finanscapes, mediascapes e ideoscapes (CANCLINI: 2005).

Por ethnoscapes podemos entender o campo que abrange as interpenetrações culturais provocadas pelos movimentos populacionais de imigração, turismo, refugiados, exilados e trabalhadores sazonais. Especificamente em São Gonçalo, percebemos essas interpenetrações sendo provocadas desde o momento de sua fundação, quando esta é realizada pelo explorador português, passando pelos ciganos, tropeiros e hyppies.

Technoscapes compreende as alterações sociais promovidas através dos fluxos produzidos pelas grandes tecnologias e empresas multinacionais. Quando estamos em São Gonçalo do Bação, não-raro escuta-se o som dos apitos de trens que trabalham diuturnamente para uma empresa exploradora de minérios. A ida dessa empresa para a região acabou provocando a desapropriação de algumas terras para o assentamento das famílias de trabalhadores, formando, deste modo, novos aglomerados habitacionais nos arredores, além de degradação e desequilíbrio ambiental com abertura de estradas para 
fluxo de produção e pela própria exploração de jazidas minerais que alteram a biodiversidade e mesmo a bela paisagem do local.

O elemento motivador - que este tipo de empreendimento utiliza para justificar os malefícios causados à sociedade por eles próprios - é o possível retorno financeiro e desenvolvimento para a região que tais obras podem gerar. Precisamos perceber isto faz parte de um universo econômico maior, do qual fazem parte os interesses do governo do Estado e dos grandes conglomerados empresariais. Essas modificações sócio-culturais ocorridas por conta de intercâmbios monetários entre os mercados nacionais e internacionais acabam refletindo no dia-a-dia de comunidades como à de São Gonçalo do Bação e classificam-se dentro da esfera do finanscapes.

Mudanças de costumes e hábitos de determinado local gerados pela mídia (Rádio, $\mathrm{TV}$, Internet, jornais, revistas, etc) e por todo o repertório de imagens e informação que são criados para distribuição em todo o planeta através da indústria cultural pertencem ao campo denominado mediascapes. Aqui vale a pena ressaltar que uma das peças do repertório do grupo de teatro - Dolores é a véia! (2000) - trata exatamente da chegada do primeiro rádio ao distrito, na década de 1930, e todas as mudanças provocadas por tal fato a partir de então.

Os ideais de democracia, liberdade, bem estar e direitos humanos quando tomados de maneira global, ou seja, transcendendo definições particulares de identidade, também provocam interpenetração tanto cultural, quanto ideológica e quando assim ocorrem são incluídas dentro da classificação denominada por Appadurai de ideoscapes. Ao tentar analisar como a interpenetração cultural ocorre por meio deste universo e como exerce influencia sobre uma comunidade como a de São Gonçalo do Bação, nos deparamos com algo que não é palpável como a relação com o “estrangeiro” já aqui mencionada, ou mesmo com a atividade mineradora na região.

Contudo, ainda assim podemos perceber tal influência começando em um campo maior, global, e se estendendo a países, estados, municípios e até mesmo distritos como o de São Gonçalo.

Por exemplo, apoiada pelos grandes poderes nacionais-populistas e pela burguesia da época, no início da década de 1950 a mídia latino-americana começa a difundir os termos “identidade nacional” e/ou "nação", fazendo com que assim os membros de cada 
sociedade se concebessem como parte de uma única e homogênea cultura. Além disso, pretendiam dessa forma realizar a identificação dos interesses políticos-partidários, ou até mesmo pessoais, como sendo também “interesses da nação", encobrindo assim a dependência perante o imperialismo e, no âmbito interno, os conflitos de classe que, tornarse-iam potenciais ameaças aos privilégios políticos (CANCLINI:1983).

Percebemos então, que quando grandes poderes tentam engendrar politicamente uma "pseudo-identidade" a alguma "nação", mesmo comunidades pacatas - como a de São Gonçalo do Bação - sofrem as conseqüências disto por não terem suas individualidades respeitadas.

\title{
“Ouro! É aqui que está o ouro!" 5: Conceito de comunidade
}

A pesquisadora Márcia Pompeo Nogueira ao iniciar a conceituação do termo comunidade em seu artigo intitulado Teatro e comunidade (2008) mostra que "quando falamos de comunidade a primeira imagem que geralmente se faz é de uma comunidade rural, pequena, estável, isolada geograficamente" (NOGUEIRA: 2008). Realmente quem passar de forma rápida por São Gonçalo do Bação chegará à conclusão que tais adjetivos caem como uma luva.

Porém o que se percebe ao permanecer por mais tempo, tomando um "cafezin" (como nos sugere o sotaque mineiro) e proseando com os habitantes do lugar é que o distrito abriga relações muito mais complexas do que as enumeradas. Márcia Pompeo nos indica que:

\begin{abstract}
A unicidade aparente das comunidades rurais são simplificações, escondem diversidades, hierarquias, baseadas em diferentes bases: idade, posição social, etc. O que daria a aparência de unicidade seria, segundo este autor, a aceitação de símbolos comuns sobre o significado da comunidade. A aceitação dos mesmos símbolos identificam uma comunidade, mesmo quando cada indivíduo o interpreta a sua maneira. Comunidade implicaria portanto em semelhanças e diferenças. (NOGUEIRA: 2008, p.2)
\end{abstract}

Certamente a convivência histórica da comunidade com o "de fora" e/ou "diferente" acaba se refletindo também no seio do grupo de teatro.

\footnotetext{
${ }^{5}$ Texto proferido pela personagem Antônio Alves Vação em A saga baçônica (1998).
} 


\section{"É porque ela foi empregada do padre e ele ensinou pra ela!" ${ }^{6}$ : A relação entre teatro e a religiosidade}

No Brasil, a maioria das manifestações populares de comunidades possui forte relação com a religiosidade. Corroboram para tal afirmação exemplos como o do Reisado, Congado, Festas Juninas, os Bois (Boi-bumbá, Bumba-meu-boi, Boi-de-mamão, etc), e tantos outros folguedos populares.

A mesma relação pode ser observada em São Gonçalo do Bação. A ligação entre a comunidade e catolicismo é presente e forte desde a fundação do distrito em 1740 e está inclusive no nome do mesmo, como já descrito. No entanto, o curioso é que por consequiência dessa proximidade com a religiosidade e fé católica do povo que o teatro começa a se tornar uma ferramenta de expressão popular.

Por conta das festividades religiosas da Semana Santa e Natal passou a ser prática recorrente no distrito que se fizessem as encenações da Paixão de Cristo e os Autos de Natal contando com a presença de pessoas da própria comunidade e utilizando como espaço de representação as ruas do distrito e o adro da igreja.

Segundo relatos, tudo era realizado de maneira repentina, de uma semana para outra ou até mesmo, de um dia para outro, sem muitos ensaios, valorizando mais a celebração coletiva em si do que o ato artístico. Algo que é extremamente plausível se pensarmos que as manifestações teatrais que hoje conhecemos e convivemos têm ancestralidade nas festas e/ou celebrações ritualísticas coletivas, seja para configurar a caça em efígie ou mesmo para celebração às divindades (BERTHOLD: 2004).

O processo de transformação que as encenações passaram, incluindo a formação do grupo de teatro, está também ligado ao nome de Mauro Ghoña. Nascido em São Gonçalo do Bação, ainda menino, na década de 1960, vai com sua família para Belo Horizonte, onde se forma em odontologia e na década de 1980 começa a estudar teatro e música em cursos realizados na cidade com artistas da região. Sempre buscou conciliar sua profissão de dentista à prática artística, onde se profissionalizou como ator participando até o início dos anos 90 de montagens teatrais belo-horizontinas.

${ }^{6}$ Texto proferido pela personagem Donana em Dolores é a véia! (2000). 
Em 1995, Mauro voltou a morar em São Gonçalo. É então que o interesse por teatro, que tanto a comunidade de São Gonçalo quanto Mauro já haviam experimentado, volta a se cruzar. Isso marca o início da historia do Grupo de Teatro de São Gonçalo do Bação.

\section{Composição de uma bela jóia}

Em 1996, é empreendida uma nova forma de se encenar da Paixão de Cristo. Os ensaios, antes inexistentes, passaram a se realizar logo após o carnaval, dando um tempo maior para o preparo dos figurinos e adereços cênicos e, principalmente, passa-se a pensar a movimentação cênica dos atores e a criação de um texto para a representação.

A resposta dada por quem assistiu, fosse da comunidade ou mesmo de outro local, foi positiva e demonstrou que a nova forma de trabalho surtira efeito. A recepção por parte do público instigou os participantes a continuarem com a mesma dinâmica nas festividades que se seguiram.

Em 1998, surge a idéia de se pesquisar a história de São Gonçalo do Bação, no intuito de encená-la. Depois de seis meses de trabalho, envolvendo pesquisas, criação de texto e ensaios, em outubro estréia $A$ saga baçônica, primeira das três peças que compõem o repertório do grupo. O elemento comum entre elas é o resgate de parte da história do distrito.

Em A saga baçônica (1998) a história da fundação do distrito por Antonio Alves Vação é encenada com base nas estórias narradas pelos habitantes e nos registros históricos pesquisados na região. Dolores é a véia! (2000), mostra em forma de comédia ligeira a chegada do primeiro rádio ao distrito de São Gonçalo, no início da década de 1930, por meio do casal Dolores e Lourival. Derrama lá, entorna cá! (2002) traz a tona o contexto em que vivia o distrito de São Gonçalo do Bação no ano de 1789, quando a Coroa Portuguesa passa a cobrar os impostos atrasados da população de forma mais veemente, sendo atribuído a este fato o nome de "Derrama".

\section{Ourivesaria}


O processo de criação parte de um longo processo de pesquisa sobre estórias antigas da região. Nesse momento, é realizado o registro em anotações ou mesmo em gravações de áudio.

No intuito de contextualizar historicamente os fatos narrados começa-se uma busca nos arquivos históricos das bibliotecas públicas da região (Belo Horizonte, Itabirito e Ouro Preto). A este material juntam-se ainda textos literários e músicas brasileiras que possuam ligação com a época em que a estória narrada se passa.

Feito todo o trabalho de pesquisa acerca do que tratará a peça, Mauro Ghoña começa a dar um tratamento dramatúrgico (AGUIAR: 2008) ao material pesquisado, engendrando diálogos, narrações, e construindo uma teia de relações entre as personagens, permeada por músicas, danças e poesias. Esta é somente "a ponta do iceberg". No período de ensaios, o grupo contribui e transforma o texto criado por meio dos jogos e dinâmicas de improvisações propostas.

Conectando estes momentos em que o grupo atravessa no seu período de criação às idéias de Enrique Buenaventura e Jacqueline Vidal acerca do trabalho de criação coletiva no Teatro Experimental de Cali (Colômbia), relaciono e acredito que o trabalho realizado em São Gonçalo do Bação possua pontos em comum com este tipo de prática.

Quando Buenaventura e Vidal remetem-se a criação coletiva de textos, tal conexão pode ser melhor elucidada:

O trabalho coletivo não elimina a divisão do trabalho, mas sim a divisão agora impede a oposição negativa entre "criadores" e "intérpretes" (mais ou menos passivos). Dentro da criação coletiva do texto se repartem tarefas de modo que o "dramaturgo" tenha a sua, assim como dentro da montagem coletiva o diretor, como vimos, não só conserva sua tarefa especifica, como esta se torna mais rica e profunda (BUENAVENTURA; VIDAL: 2006, p.41).

Um processo semelhante pôde ser observado no breve período em que estive com o grupo. Lá percebi que além de atuar - de acordo com as suas aptidões pessoais e profissionais - cada participante tem uma função dentro do grupo. Assim, além de fazerem parte do elenco, muitos trabalham na confecção dos cenários, figurinos e adereços de cena, edição das músicas e sonoplastias, assistência de direção, arte gráfica, maquiagem, etc. 
Marilene Mendonça, quando questionada sobre sua importância enquanto assistente de direção, nos indica uma possibilidade de leitura de como se estabelecem tais relações dentro do grupo:

Isso só acontece porque somos um todo. A gente talvez só tenha essa importância por conta do todo, sabe? Por que se não a gente não teria. Então eu sempre tenho esse cuidado e esse zelo com o todo. Não acho que somos mais que nada ou que ninguém. É o todo que faz isso acontecer. Por que se existíssemos só eu e Mauro cheios de boas intenções, cheios de idéias, de que adiantaria? (MENDONÇA em entrevista concedida em 08/06/2008)

Sob este aspecto percebemos, ao invés de uma relação hierarquizante, a pluralidade e aceitação das diferenças dentro do trabalho do grupo e, consequientemente, a valorização do coletivo.

\section{"ÊE, sina minha de beber cachaça e fazer mau negócio!"”: Importância do grupo para a região.}

Se optarmos pelo pragmatismo, e formos em busca da real importância que o grupo de teatro possui para a comunidade e para as pessoas que participam, talvez a resposta esteja no aspecto de coletividade analisado acima.

Nas entrevistas realizadas com os participantes do grupo e da comunidade, outros pontos foram levantados, como por exemplo, o crescimento da auto-estima ${ }^{8}$ de cada integrante do grupo e até mesmo da comunidade que tornou-se conhecida na região pelo trabalho do grupo.

O resgate da memória e identidade do $\operatorname{local}^{9}$ que ganha significado por meio dos temas abordados nas peças contribuindo, como evidencia o pesquisador Ramon Aguiar (2008), de forma a que a memória pessoal dos participantes e entrevistados construíssem, através do teatro, uma memória coletiva dos episódios vividos em cena (AGUIAR: 2008, p.4).

\footnotetext{
${ }^{7}$ Várias personagens em Derrama lá, entorna cá! (2002).

${ }^{8}$ Citada nas entrevistas realizadas com: D. Avenina (07/06/2008), Maria Aparecida Abreu Guatimosim (06/06/2008), Marilene Mendonça (08/06/2008), Mauro Ghoña (08/06/2008).

${ }^{9}$ Citada na entrevista realizada com Ramon Aguiar em 07/06/2008.
} 
O desenvolvimento intelectual dos integrantes, por conta das leituras realizadas nos

ensaios $^{10}$, além do movimento cultural provocado na região ${ }^{11}$, sendo que hoje o município de Itabirito possui ainda mais três grupos teatrais surgidos depois do grupo de São Gonçalo.

Ou seja, o fazer teatral do grupo é realizado em plena interação com a comunidade de São Gonçalo do Bação emprestando assim uma característica popular ao trabalho.

\section{Culturas populares. Assim, no plural mesmo!}

Encontrar uma definição para o termo "popular" não é tão fácil quanto se possa parecer, ainda mais quando a palavra precedente for "cultura". Há que se tomar cuidado quando da utilização do termo "cultura popular" em sua forma singular, pela falsa impressão de homogeneidade que carrega. Não existe uma única cultura popular, do contrário, diversas culturas populares, termo que aqui acreditamos ser mais pertinente.

Além disso, existe uma grande diferença entre a noção de "cultura" nos idos do século XIX (marcado pela "descoberta" do povo por parte dos intelectuais europeus) e atualmente. Enquanto no passado o termo era utilizado para a designação das artes, literatura, ciência e religião; atualmente, se fala em "cultura" de forma muito mais ampla e até mesmo banalizada fazendo-se referência a quase tudo que pode ser aprendido dentro de uma sociedade (BURKE: 1996), passando pelo modo de comer, falar, beber, andar, se vestir, etc. O que antigamente era considerado como "senso comum" ou "hábito", hoje é visto como algo que varia de sociedade para sociedade, que muda com o passar dos séculos e que sendo construído socialmente necessita de explicação e interpretação sócio-histórica.

O historiador britânico Peter Burke é enfático ao falar que as culturas populares não são homogêneas, possuem variações regionais, variações segundo a ocupação da pessoa. A cultura do camponês não é a mesma que a do artesão; a cultura do camponês criador de gado não é a mesma do camponês que se dedica à agricultura (BURKE: 1996).

Canclini empreende visão semelhante ao propor o afastamento da visão romântica que concebe a cultura popular como sendo detentora de pureza absoluta, como se as mesmas não tivessem contato com o desenvolvimento capitalista e não fosse a própria uma

\footnotetext{
${ }^{10}$ Citado na entrevista realizada com Devanir Vitor Lopes em 06/06/2008.

${ }^{11}$ Citado na entrevista realizada com Mauro Ghoña em 08/06/2008.
} 
resultante da absorção da ideologia dominante e das contradições entre as classes oprimidas.

Segundo o autor, a interação e reconfiguração da cultura dominante através de símbolos e significações próprias conferem características populares à determinada cultura. A forma como tais características são empregadas também merece especial atenção como nos sugere abaixo:

\footnotetext{
Nenhum objeto tem o seu caráter popular garantido para sempre porque foi produzido pelo povo ou porque este consome com avidez; o sentido e o valor populares vão sendo conquistados nas relações sociais. É o uso e não a origem, a posição e a capacidade de suscitar práticas ou representações populares, que confere essa identidade. (CANCLINI: 1983, p.135)
}

Observamos que o Grupo de Teatro de São Gonçalo do Bação configura-se como uma importante ferramenta de expressão popular por carregar no âmago de seu trabalho o anseio da comunidade em resgatar sua memória e preservar sua identidade cultural.

\section{É isso, uai!: Conclusão.}

Tal resgate pode aqui ser compreendido como sendo uma vontade também da comunidade. Aqui expusemos vários processos que dão margem a analise de como a interpenetração cultural ocorreu/ocorre em São Gonçalo do Bação (os scapes supracitados).

Se por um lado essa interpenetração provocou tamanha diversidade cultural, por outro pode se tornar uma ameaça a preservação da identidade e ao próprio crescimento do local.

Portanto, o papel do grupo de teatro é importantíssimo. Pois, sendo um símbolo comum aos habitantes de São Gonçalo, fortalece a comunidade quando esta se enxerga dentro das peças apresentadas, percebendo a história do local onde nasceu sendo recontada ou mesmo enquanto personagem das tramas.

\section{Bibliografia}


AGUIAR, Ramon Santana. "Espaço e memória na cena teatral: O Teatro de São Gonçalo do Bação e a construção de um espaço mnemônico na História do Espetáculo”. In: LIMA, Evelyn Furquim Werneck. (Org.). Espaço e teatro. Do edifício teatral à cidade como palco. Rio de Janeiro: 7 Letras/FAPERJ, 2008, v. 1, p. 213-238.

AGUIAR, Ramon Santana. Memória e espaço: o Teatro comunitário de São Gonçalo do Bação. Dissertação (Mestrado em Teatro)- Universidade Federal da Cidade do Rio de Janeiro, Rio de Janeiro, 2006.

BERTHOLD, Margot. História mundial do teatro. São Paulo: Perspectiva, 2004.

BUENAVENTURA, Enrique; VIDAL, Jacqueline.. "Notas para um método de criação coletiva". In: Revista Camarim. São Paulo: Cooperativa paulista de teatro, 2006, Ano 9, n³7, p. 30-42.

BURKE, Peter. Cultura popular na Idade Moderna: Europa, 1500-1800. São Paulo: Companhia das Letras, 1995.

. Culturas populares e cultura de elite. Palestra proferida, em 23/03/1996, na Universidade Estadual de Maringá - UEM - Maringá/PR. Disponível em: http://www.dhi.uem.br/publicacoesdhi/dialogos/volume01/Rev_a01.htm. Acesso: 29/01/2008 às 20hs00min.

GARCÍA CANCLINI, Néstor. Consumidores e cidadãos: conflitos multiculturais da globalização. 5. ed. Rio de Janeiro: UFRJ, 2005.

. As culturas populares no capitalismo. São Paulo: Brasiliense, 1983.

NOGUEIRA, Márcia Pompeo. "Teatro e comunidade" in: FLORENTINO, Adilson; TELLES, Narciso (org.). Cartografias do Ensino de Teatro: das idéias às práticas. $\quad$ Uberlândia: UDUFU, 2008. (no prelo).

Textos dramáticos

GRUPO DE TEATRO DE SÃO GONÇALO DO BAÇÃO. A saga baçônica. Criação coletiva. 1998.

. Dolores é a veia. Criação coletiva. 2000.

.Derrama lá, entorna cá. Criação coletiva. 2002. 